\title{
Versatility of Supported Gold Nanoparticles on Hydrotalcites used for Oxidation and Reduction Reactions
}

Fabien Drault ${ }^{1}$, Youssef Snoussi ${ }^{1}$, Camila P. Ferraz ${ }^{1}$, Joelle Thuriot-Roukos ${ }^{1}$, Svetlana Heyte ${ }^{1}$, Ivaldo Itabaiana Junior ${ }^{1,2}$, Maya Marinova ${ }^{3}$, Sébastien Paul ${ }^{1}$, Robert Wojcieszak ${ }^{1,}$ *

1. Univ. Lille, CNRS, Centrale Lille, Univ. Artois, UMR 8181 - UCCS - Unité de Catalyse et Chimie du Solide, F-59000 Lille, France; E-Mails: fabien.drault@univ-lille.fr; youssef.snoussi@univ-lille.fr; camila.palombo-ferraz@centralelille.fr; joelle.thuriot@univ-lille.fr; svetlana.heyte@univ-lille.fr; ivaldo.itabaiana@univ-lille.fr; sebastien.paul@centralelille.fr; robert.wojcieszak@univ-lille.fr

2. Department of Biochemical Engineering, School of Chemistry, Federal University of Rio de Janeiro, Rio de Janeiro 21941-910, Brazil

3. Univ. Lille, CNRS, INRA, Centrale Lille, Univ. Artois, FR 2638 - IMEC - Institut Michel-Eugène Chevreul, F-59000 Lille, France; E-Mail: maya.marinova@univ-lille.fr

* Correspondence: Robert Wojcieszak; E-Mail: robert.wojcieszak@univ-lille.fr

Academic Editor: Yan Jiao

Special Issue: Recent Advances in Catalysis for Biomass Conversion

Catalysis Research

2022, volume 2, issue 1

doi:10.21926/cr.2201001
Received: October 25, 2021

Accepted: January 05, 2022

Published: January 13, 2022

\begin{abstract}
Regardless of their size, supported gold nanoparticles are largely used for liquid-phase oxidation reactions. Small gold nanoparticles exhibit good performance during the reduction of organic compounds. The direct reduction of carboxylic acid to aldehyde is a famous and familiar reaction in the field of organic chemistry and is considered as one of the fundamental chemical transformations. Herein, we present $\mathrm{Au} / \mathrm{hydrotalcite,} \mathrm{Au} / \mathrm{MgO}$, and $\mathrm{Au} / \mathrm{Al}_{2} \mathrm{O}_{3}$ systems as heterogeneous versatile catalysts to realize the oxidation of furfural (FF) to furoic acid (FA) and realize the reduction of FA to FF. Experiments showed that in standard aqueous conditions under air, FF can be easily oxidized to FA. When DMSO was used as a solvent to conduct the experiments under an atmosphere of $\mathrm{CO}_{2}$, $\mathrm{FA}$ was reduced to FF. The $\mathrm{Au} / \mathrm{HT}$ series
\end{abstract}

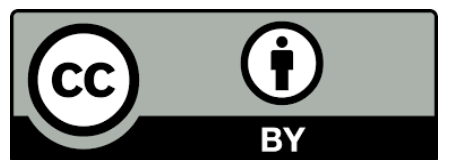

(c) 2022 by the author. This is an open access article distributed under the conditions of the Creative Commons by Attribution License, which permits unrestricted use, distribution, and reproduction in any medium or format, provided the original work is correctly cited. 
of catalysts was found to be active in both transformations, pointing out the versatility of the gold-based catalysts. The activity significantly depends on the acid-base properties of the catalyst.

\section{Keywords}

Gold nanoparticles; catalysis; furfural; $\mathrm{CO}_{2}$; reduction; oxidation

\section{Introduction}

The development and understanding of efficient technologies for the production of platform molecules (small molecules derivable from biomass used as building blocks for chemical industry) and valuable chemicals from renewable biomass have attracted immense attention from researchers [1-4]. Until now, the direct partial reduction of carboxylic acid to the corresponding aldehyde using heterogeneous catalysts has been rarely discussed in the literature [5]. Over the years, researchers have primarily focused on the oxidation of aldehydes to acids and not on the reverse reaction [6-8]. However, aldehydes (such as furfural (FF)) are one the most common building blocks used in fine chemicals synthesis (in the cosmetic, pharmaceutical, and agrochemical industry) [9]. They are conventionally produced following several techniques [10-13]. The use of these techniques results in the formation of undesirable by-products, and this affects the product yields. The generated waste has to be treated later. In the field of biocatalysis, the use of enzymatic catalysts, e.g., carboxylic acid reductase (CAR), promotes the conversion of fatty aldehydes to the corresponding fatty carboxylic acids avoiding the production of the corresponding alcohols [13, 14]. The reduction of carboxylic acid has been extensively studied under conditions of non-catalytic and homogeneous catalytic reactions using different reducing agents [9-12]. The metal hydride-based reducing agents, such as lithium aluminum hydride, borane, and silanes, are generally used to produce aromatic aldehydes $[15,16]$. Typically, the process involves protecting the acid functional group to form the trimethylsilyl ester (TMS ester)-based product prior to conducting the reduction reaction at $-78^{\circ} \mathrm{C}$ using di-isobutylaluminum hydride (DIBAL-H) [16]. Under these conditions, the aldehyde is produced in $60-70 \%$ yield. FF can be produced from 2-furoic acid (FA) using this method or using hypervalent silicon hydrides [15]. As the production of organic intermediates (such as aldehydes) is of high industrial interest, the use of heterogeneous catalysts is of enormous interest as it makes the separation of the catalyst from the reactional media easy. Thus, the amount of reaction waste produced could also be largely decreased. This is interesting from an environmental point of view.

Furthermore, the synthesis of aldehydes often requires the use of sensitive reagents under harsh reaction conditions. The use of heterogeneous catalysts could improve the selectivity of the process and, as previously mentioned, help decrease the amount of harmful wastes produced. The direct reduction of carboxylic acid was first studied using copper chromite $[17,18]$ and several other metal oxides [19-21]. However, alcohols are produced when this method is used. There is no possibility of obtaining aldehydes that are easily hydrogenated under these conditions [18, 22-24]. The hydrogenation of carboxylic acids into aldehydes using heterogeneous catalysts is generally performed in a gas-phase reactor under conditions of high temperatures $\left(300-500{ }^{\circ} \mathrm{C}\right)[25,26]$. 
Sakata et al. [26] obtained $90 \%$ yield of benzaldehyde by hydrogenating benzoic acid using $\mathrm{CeO}_{2}$ as the catalyst at $375^{\circ} \mathrm{C}$ (pressure: 1 bar of $\mathrm{H}_{2}$ ). Yokoyama et al. [25] reported the acid-basic influence of several metal oxides, such as $\mathrm{ZrO}_{2}$ and $\mathrm{Cr}_{2} \mathrm{O}_{3}$, on aldehyde selectivity. They concluded that the surface of the catalyst should not contain any strongly basic or acidic sites, and the surface should not be characterized by weak redox properties to improve the catalytic performances. Hydrotalcites (HTs) emerge as prominent catalyst candidates when the above-mentioned conclusions are taken into account. The HTs, used as supports, are solid samples with interesting structural properties. $\mathrm{HTs}$ are layered clays containing $\mathrm{OH}^{-}$and $\mathrm{HCO}_{3}$-groups on the surface. They exhibit high activity during base catalyzed reactions. The HT-based catalysts have shown remarkable performance during several reactions such as aldol condensation, 5-hydroxymethylfurfural (HMF) oxidation, and transesterification [27-30]. Metals supported on HTs are excellent bifunctional catalysts as different active sites (metal and basic active sites) can be generated. This can be attributed to the close proximity between the metal species and the support [31].

Recently, Roselli et al. [32] studied the conversion of FF to FA using Au/HTs catalysts. Water was used as the reaction medium, and the reaction was carried out at $110{ }^{\circ} \mathrm{C}$ under a pressure of 6 bar of $\mathrm{O}_{2}$. The researchers pointed out that when the $\mathrm{Mg}$ :Al molar ratio in the HT supports is increased, the yield of FA increases from 70 to $100 \%$ (Figure 1, upper part). The increase in the activity of the $\mathrm{Au} / \mathrm{HT}$ catalysts was attributed to the increase in the overall basicity of the HT supports prepared under varying $\mathrm{Mg}$ :Al ratios.

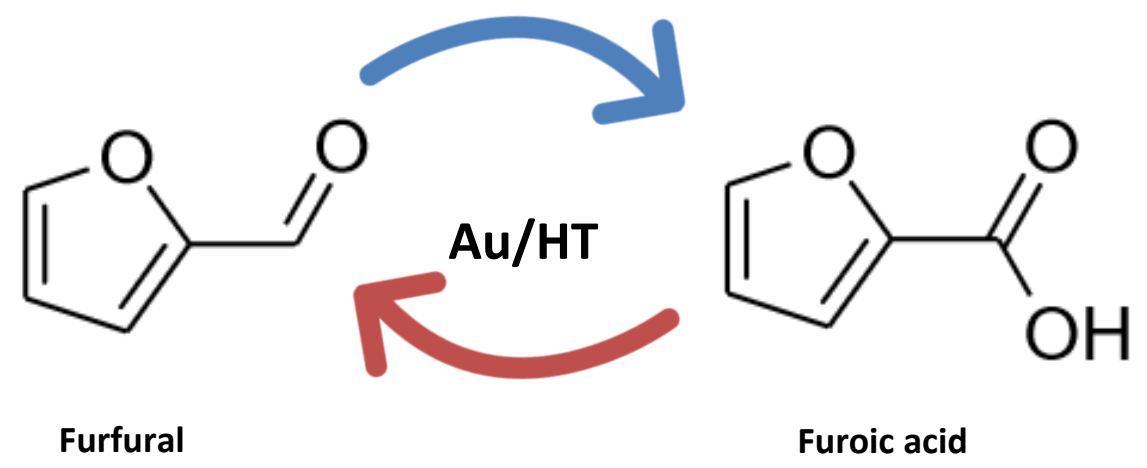

Figure 1 Reaction scheme of the oxidation of furfural (FF) (using $\mathrm{O}_{2}$ ) and reduction of furoic acid (FA) to FF (using $\mathrm{CO}_{2}$ ) on Au-based catalysts.

Herein the versatility of the Au-based catalysts supported on HTs is discussed by carrying out the reduction of FA to FF (Figure 1). Thus, the main objective of this work is to understand if FA can be reduced using supported gold nanoparticles. To the best of our knowledge, this is the first report on the direct reduction of FA using supported gold catalysts. We decided to perform the reaction in the liquid phase using a batch reactor under pressurized conditions to decrease the reaction temperature (energy gain) and avoid the degradation of the reactants/products. The effect of the structural and textural properties of $\mathrm{MgO}, \mathrm{Al}_{2} \mathrm{O}_{3}$, and the $\mathrm{HTs}$ supports on the reaction efficiency under conditions of varying $\mathrm{Mg}$ : Al molar ratios have also been studied. 


\section{Materials and Methods}

\subsection{Catalyst Preparation}

A series of HT supports were prepared by co-precipitating an aqueous solution of magnesium and aluminum salts with a highly basic solution of $\mathrm{NaOH}$ and $\mathrm{Na}_{2} \mathrm{CO}_{3} \bullet 10 \mathrm{H}_{2} \mathrm{O}$ (99.5\%, Sigma-Aldrich) [33]. Different molar ratios of $\mathrm{Mg}: \mathrm{Al}(3: 1,2: 1,1: 1$, and 3:1) were used to prepare the supports labeled $\mathrm{HT} 3: 1, \mathrm{HT}$ 2:1, $\mathrm{HT}$ 1:3, and $\mathrm{HT} 3: 1$, respectively. The $\mathrm{Mg}\left(\mathrm{NO}_{3}\right)_{2} \bullet 6 \mathrm{H}_{2} \mathrm{O}$ (99.9\%, Sigma-Aldrich) and $\mathrm{Al}\left(\mathrm{NO}_{3}\right)_{3} \bullet 9 \mathrm{H}_{2} \mathrm{O}(99.9 \%$, Sigma-Aldrich) precursor solutions were added dropwise to a solution of $\mathrm{NaOH}(1 \mathrm{M})$, and the $\mathrm{pH}$ was maintained in the range of $10.5 \pm 0.1$ at a temperature of $55{ }^{\circ} \mathrm{C}$. After $1 \mathrm{~h}$ of stirring ( $600 \mathrm{rpm}$ ) at a constant temperature, the suspension was filtered, and the solid was washed with $100 \mathrm{~mL}$ of warm distilled water $\left(50^{\circ} \mathrm{C}\right)$. Following this, the sample was further dried overnight at $100{ }^{\circ} \mathrm{C}$. The Au nanoparticles were prepared following a sol immobilization method reported in the literature $[1,2,34] . \mathrm{NaBH}_{4}$ and polyvinyl alcohol (PVA) were used as the reducing and dispersing agents, respectively. Typically, an aqueous solution of 2 wt.\% PVA was added to an aqueous solution of $\mathrm{HAuCl}_{4}\left(5 \times 10^{-4} \mathrm{~mol} \mathrm{~L}^{-1}\right)$ under conditions of vigorous stirring (1000 $\mathrm{rpm})(\mathrm{PVA} / \mathrm{Au}(\mathrm{w} / \mathrm{w})=1.2)$ at $25^{\circ} \mathrm{C}$. Following this, a freshly prepared solution of $\mathrm{NaBH}_{4}\left(0.1 \mathrm{~mol} \mathrm{~L}^{-}\right.$ 1; $\mathrm{NaBH}_{4} /$ Au molar ratio of 5:1) was added to the previous solution to form the metallic sol (color = deep purple). After $30 \mathrm{~min}$, the Au nanoparticles were immobilized by adding the support (MgO, $\mathrm{Au} / \mathrm{HT}$ series, and $\left.\mathrm{Al}_{2} \mathrm{O}_{3}\right)$ under conditions of vigorous stirring $(1000 \mathrm{rpm})$ at RT. The amount of support added was determined to obtain catalysts containing $2 \mathrm{wt} . \% \mathrm{Au}$. The mixture was filtered after $2 \mathrm{~h}$, and the solid was washed 3 times with warm water $\left(3 \times 100 \mathrm{~mL} ; 50^{\circ} \mathrm{C}\right)$ and 3 times $(3 \times 100$ $\mathrm{mL}$ ) with ethanol. Subsequently, the sample was further dried at $100^{\circ} \mathrm{C}$ for $1 \mathrm{~h}$. The solids obtained were labelled as Au/HT 3:1, Au/HT 2:1, Au/HT 1:1, and Au/HT 1:3. The expected particle sizes of the Au-supported catalysts were approximately in the range of $2-4 \mathrm{~nm}$.

\subsection{Catalytic Test}

FF was synthesized in a Top Industry autoclave reactor. Typically, the reactor was loaded with 15 $\mathrm{mg}$ of FA mechanically mixed with $50 \mathrm{mg}$ of the catalyst. To this mixture, $20 \mathrm{~mL}$ of dimethyl sulfoxide (DMSO) was added. DMSO was chosen as the reaction solvent after conducting preliminary tests with various organic solvents (such as acetonitrile, methanol, and DMSO). The best results were obtained. Water, used for the oxidation of FF to FA, was excluded because of the low stability of $\mathrm{MgO}$ and $\mathrm{HT}$ in water. Leaching of these compounds was observed during the oxidation reaction as the stabilities of these compounds were low. The catalytic test was performed under a pressure of 15 bar of $\mathrm{CO}_{2}$ at $150{ }^{\circ} \mathrm{C}$ (conditions: $600 \mathrm{rpm}, 24 \mathrm{~h}$ ). Following this, the media were filtered. The conversion yields were monitored using an High Performance Liquid Chromathography - HPLC (Waters $2410 \mathrm{RJ}$ ) system equipped with a UV detector and a Shodex SUGAR SH-1011 column using $5 \mathrm{mM}$ of $\mathrm{H}_{2} \mathrm{SO}_{4}\left(0.6 \mathrm{~mL} \mathrm{~min}{ }^{-1}\right)$ as the mobile phase.

\subsection{Characterization Techniques}

Temperature Programmed Desorption of $\mathrm{NH}_{3}\left(\mathrm{NH}_{3}-\mathrm{TPD}\right)$ and $\mathrm{CO}_{2}\left(\mathrm{CO}_{2}-\mathrm{TPD}\right)$ experiments were performed at $50{ }^{\circ} \mathrm{C}$ and $40{ }^{\circ} \mathrm{C}$, respectively. The reactions were conducted for $1 \mathrm{~h}$ using $10 \% \mathrm{NH}_{3}$ or $10 \% \mathrm{CO}_{2}$ in the He gas mixture. Prior to the desorption step, helium was flown through the supports 
for $30 \mathrm{~min}$. Following this, the temperature was increased to $500{ }^{\circ} \mathrm{C}$ (heating rate: $10{ }^{\circ} \mathrm{C} \mathrm{min}^{-1}$ ), which is the calcination temperature used to prepare the HT supports [33]. This temperature was maintained for $1 \mathrm{~h}$. The quantity of desorbed $\mathrm{CO}_{2}$ or $\mathrm{NH}_{3}$ was measured using a TCD.

The X-ray diffraction (XRD) patterns of the solids were recorded using a Bruker D8-ADVANCE powder XRD machine equipped with a CuK $\alpha$ radiation source $(L=0.1538 \mathrm{~nm})$ operating at an accelerating voltage of $40 \mathrm{kV}$. The emission current was $40 \mathrm{~mA}$, and the intensity data were collected over a $2 \theta$ range of $10-70^{\circ}$. The step size was $0.014^{\circ}$, and a time counter of $0.1 \mathrm{~s}$ per step was used.

The composition of the Au catalysts was determined using the inductively coupled plasma-optical emission spectroscopy (ICP-OES) technique. The data were recorded using the Agilent 720-ES equipment. A Vulcan $42 \mathrm{~S}$ automated digester was coupled to the system. The solid samples (10 mg) were digested using $4 \mathrm{~mL}$ of aqua regia and heated to $110^{\circ} \mathrm{C}$ for $2 \mathrm{~h}$.

The specific surface area (Brunauer-Emmett-Teller, BET) and average pore size (Barrett_Joyner_Halenda, BJH) of the gold catalysts were determined by conducting the nitrogen adsorption and desorption analysis tests at $-196{ }^{\circ} \mathrm{C}$ using a TriStar II Plus analyzer (Norcross, GA, USA) (Micromeritics). Prior to conducting the experiments, the samples were heated at $250^{\circ} \mathrm{C}\left(10^{\circ} \mathrm{C}\right.$ $\mathrm{min}^{-1}$ ). This temperature was maintained for $1 \mathrm{~h}$ under conditions of vacuum.

The transmission electron microscopy (TEM) technique was used to record images using a TEM/scanning FEI TECNAI F20 microscope combined with an energy dispersive X-ray spectrometer (EDS) at $200 \mathrm{kV}$. Prior to conducting the experiments, the samples were dispersed in $1 \mathrm{~mL}$ of ethanol and left for $10 \mathrm{~min}$ in an ultrasonic bath. The diameters of 100 particles (as a minimum) were measured from the TEM images and used for statistical analyses to calculate the average size of the gold nanoparticles.

\section{Results}

Structural and textural properties of the catalysts were studied to correlate the catalytic performances with the different properties of the catalysts. Firstly, the acid-base properties of the supports were evaluated by studying the TPD of $\mathrm{NH}_{3}$ and $\mathrm{CO}_{2}$. The TPD profiles are illustrated in Figure 2.
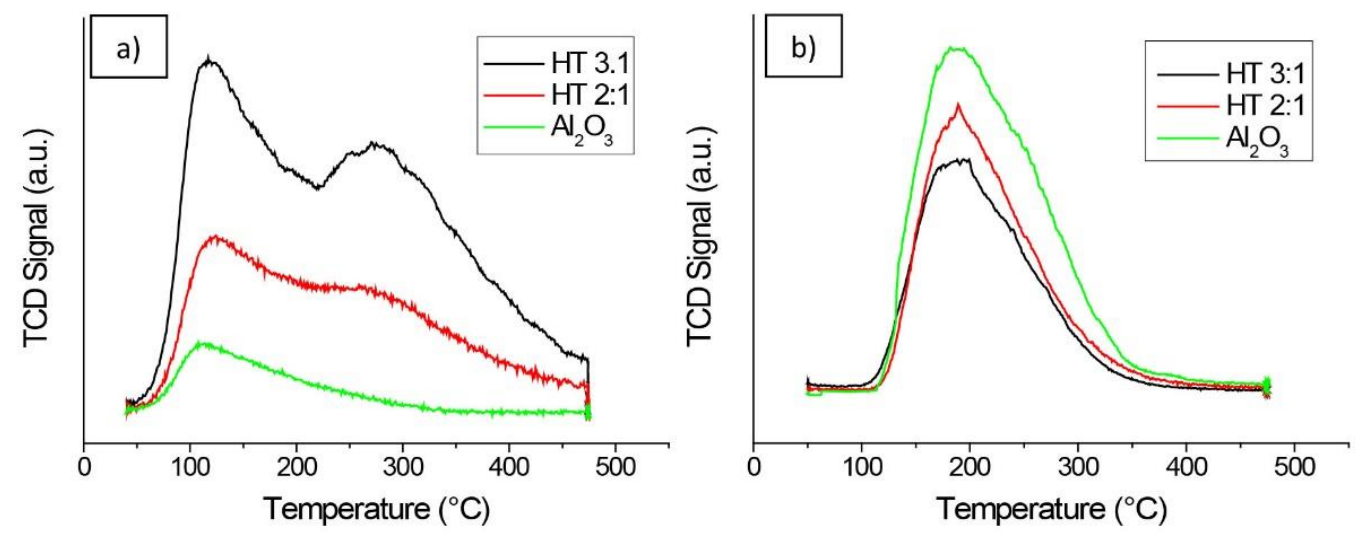

Figure 2 Temperature Programmed Desoprtion profiles of (a) $\mathrm{CO}_{2}\left(\mathrm{CO}_{2}-\mathrm{TPD}\right)$ and (b) $\mathrm{NH}_{3}$ $\left(\mathrm{NH}_{3}-\mathrm{TPD}\right)$ recorded for the $\mathrm{HTs}$ under conditions of varying $\mathrm{Mg}: \mathrm{Al}$ molar ratios and in the presence of $\mathrm{Al}_{2} \mathrm{O}_{3}$. 
In the case of HTs, when the Mg:Al ratios were 2:1 and 1:1, similar desorption results were obtained. The HT 3:1 desorption led to expected results. The amount of $\mathrm{NH}_{3}$ adsorbed was less, and the amount of $\mathrm{CO}_{2}$ adsorbed was more than those observed for the two other HTs. It is noteworthy that the HTs are characterized by the presence of weak or weak to medium acidic sites. This is validated by the presence of one large peak corresponding to $\mathrm{NH}_{3}$ desorption. The peak maximum was located at approximately $190^{\circ} \mathrm{C}$ [35]. For the $\mathrm{CO}_{2}$ desorption process, two peaks were observed at approximately $120{ }^{\circ} \mathrm{C}$, and $275^{\circ} \mathrm{C}$, which corresponded to the weak and strong basic sites, respectively, for all the HTs studied [28]. Table 1 presents the amounts of $\mathrm{NH}_{3}$ and $\mathrm{CO}_{2}$ desorbed during the TPD-based experiments in arbitrary units per gram of the material.

Table 1 TPD-based $\mathrm{NH}_{3}$ and $\mathrm{CO}_{2}$ desorption results obtained for the different supports.

\begin{tabular}{|c|c|c|}
\hline Catalyst & $\mathrm{NH}_{3}\left(\right.$ a. u.g $\left.\mathrm{g}^{-1}\right)$ & $\mathrm{CO}_{2}\left(\right.$ a. u.g $\left.{ }^{-1}\right)$ \\
\hline $\mathrm{MgO}$ & - & 265 \\
\hline HT (3:1) & 62 & 69 \\
\hline $\mathrm{HT}(2: 1)$ & 90 & 33 \\
\hline HT (1:1) & 89 & 32 \\
\hline $\mathrm{Al}_{2} \mathrm{O}_{3}$ & 103 & 8 \\
\hline
\end{tabular}

The XRD patterns of the Au/HTs catalysts are illustrated in Figure 3. XRD diffractograms obtained for each $\mathrm{Au} / \mathrm{HT}$ catalyst showed the presence of typical diffraction peaks corresponding to HT (powder diffraction file 89-460 from ICDD). The presence of periclase (MgO) in the HT solids and $\mathrm{Au} / \mathrm{MgO}$ catalyst was also observed when the patterns were analyzed. This is validated by the presence of the diffraction peaks at $2 \theta=38^{\circ}, 43^{\circ}$, and $63^{\circ}$. As expected, the intensities of these peaks increase with the Mg:Al ratio in the HTs supports. When the XRD patterns were recorded for the $\mathrm{Au} / \mathrm{Al}_{2} \mathrm{O}_{3}$ catalyst, characteristic diffraction peaks corresponding to $-\mathrm{Al}_{2} \mathrm{O}_{3}$ were found to be present at $2 \theta=38,46^{\circ}$, and $67^{\circ}$. In all cases, diffraction peaks corresponding to metallic gold were not observed, indicating the small size of the gold nanoparticles $(<3 \mathrm{~nm})$. 


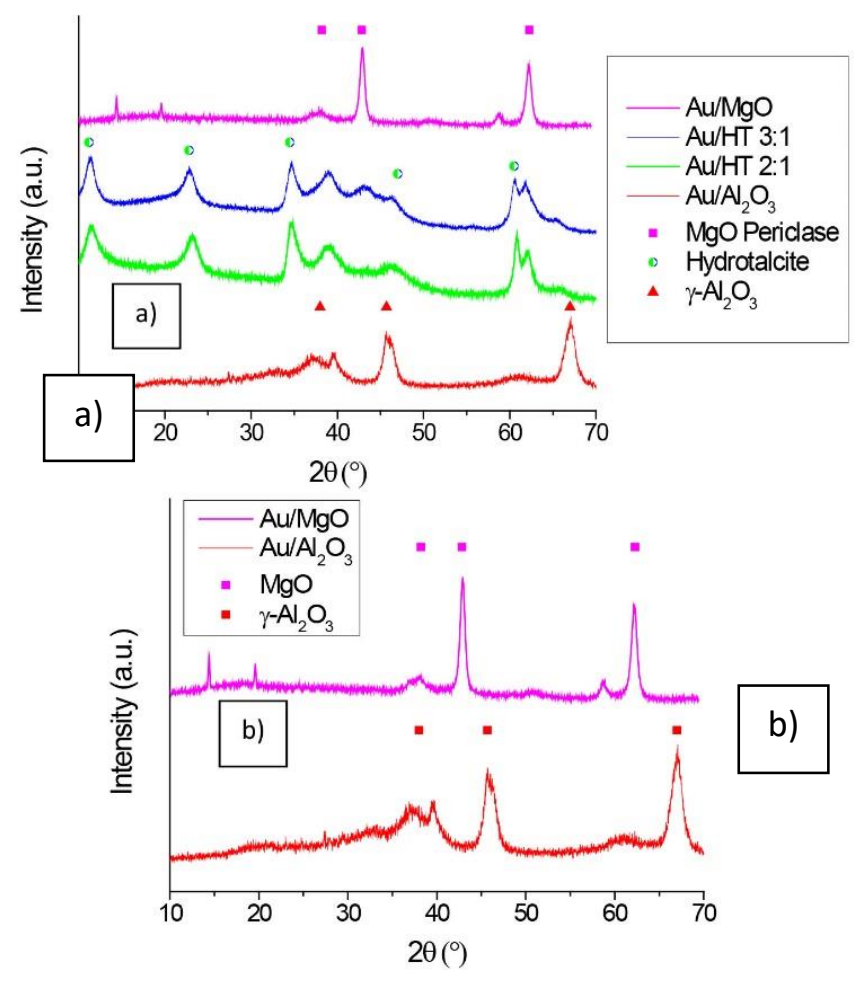

Figure $3 \mathrm{X}$-ray diffraction (XRD) patterns recorded for (a) gold supported on different hydrotalcites (HTs) and (b) $\mathrm{Au} / \mathrm{MgO}$ and $\mathrm{Au} / \mathrm{Al}_{2} \mathrm{O}_{3}$ systems.

Following the sol-immobilization of $\mathrm{Au}$ on the supports, the inductively coupled plasma-optical emission spectroscopy (ICP-OES) technique was used to analyze the catalysts to determine the gold content in each catalyst (nominal value: $2 \mathrm{wt} . \%$ ), and the $\mathrm{Mg} / \mathrm{Al}$ molar ratio in the HT supports (theoretical values: 3, 2, and 1). The Al, $\mathrm{Au}$, and $\mathrm{Mg}$ contents are presented in Table 2. The experimentally obtained $\mathrm{Mg}$ :Al molar ratio in the Au/HTs samples contained a lower proportion of $\mathrm{Mg}$ than what was expected. A deviation of approximately $20 \%$ from the theoretical value was registered. The Au content in the catalysts was lower than expected, and the values ranged from 1.5 to 1.8 wt.\%.

Table 2 Chemical composition and textural properties of the Au-supported catalysts.

\begin{tabular}{|c|c|c|c|c|c|}
\hline Catalyst & $\begin{array}{l}\text { Molar } \\
\text { Mg:Al }\end{array}$ & ratio & \%wt Au & S BET $\left(m^{2} g^{-1}\right)$ & $\begin{array}{l}\text { Pore volume } \\
\left(\mathrm{cm}^{3} \mathrm{~g}^{-1}\right)\end{array}$ \\
\hline $\mathrm{Au} / \mathrm{MgO}$ & - & & 1.6 & 106 & 0.52 \\
\hline $\mathrm{Au} / \mathrm{HT}(3: 1)$ & 2.5 & & 1.7 & 25 & 0.07 \\
\hline $\mathrm{Au} / \mathrm{HT}(2: 1)$ & 1.7 & & 1.5 & 73 & 0.17 \\
\hline $\mathrm{Au} / \mathrm{HT}(1: 1)$ & 0.7 & & 1.8 & 73 & 0.17 \\
\hline $\mathrm{Au} / \mathrm{Al}_{2} \mathrm{O}_{3}$ & - & & 1.7 & 132 & 0.37 \\
\hline
\end{tabular}

The specific surface areas (BET) and pore volumes (BJH) are compiled in Table 2. The surface areas and pore volumes increased from the highest $\mathrm{Mg} / \mathrm{Al}$ molar ratio ( $\mathrm{Au} / \mathrm{HT} 3: 1$ ) to the lowest $\mathrm{Mg} / \mathrm{Al}$ molar ratio (Au/HTs 1:1). It shows the influence of the deposition method of the gold 
nanoparticles on the textural properties of the support. The gold nanoparticles block the pores, and this influences the process of intraparticle diffusion. However, the surface areas and pore volumes of the Au/HTs (2:1) and (1:1) catalysts were similar, and the areas were $73 \mathrm{~m}^{2} \mathrm{~g}^{-1}$ and $0.17 \mathrm{~cm}^{3} \mathrm{~g}^{-1}$, respectively. The specific surface areas and pore volumes of the $\mathrm{Au} / \mathrm{Al}_{2} \mathrm{O}_{3}$ and $\mathrm{Au} / \mathrm{MgO}$ catalysts were higher than the specific surface area and pore volume of the Au/HTs catalyst. As the catalytic performances of these two catalysts were in stark contrast with each other, it appears that the specific surface area and the pore volume do not influence the reaction.

The Au-based catalysts were also characterized using the TEM technique (Figure 4) to determine the extent of metal dispersion achieved on the support surface. Analysis of the images reveals that the gold nanoparticles were highly dispersed on the surface in all cases. The average particles size was $3.7 \mathrm{~nm}$ (determined by studying approximately 100 particles) for the $\mathrm{Au} / \mathrm{Al}_{2} \mathrm{O}_{3}$ sample. This also confirmed the stability of the gold nanoparticles during the immobilization step.
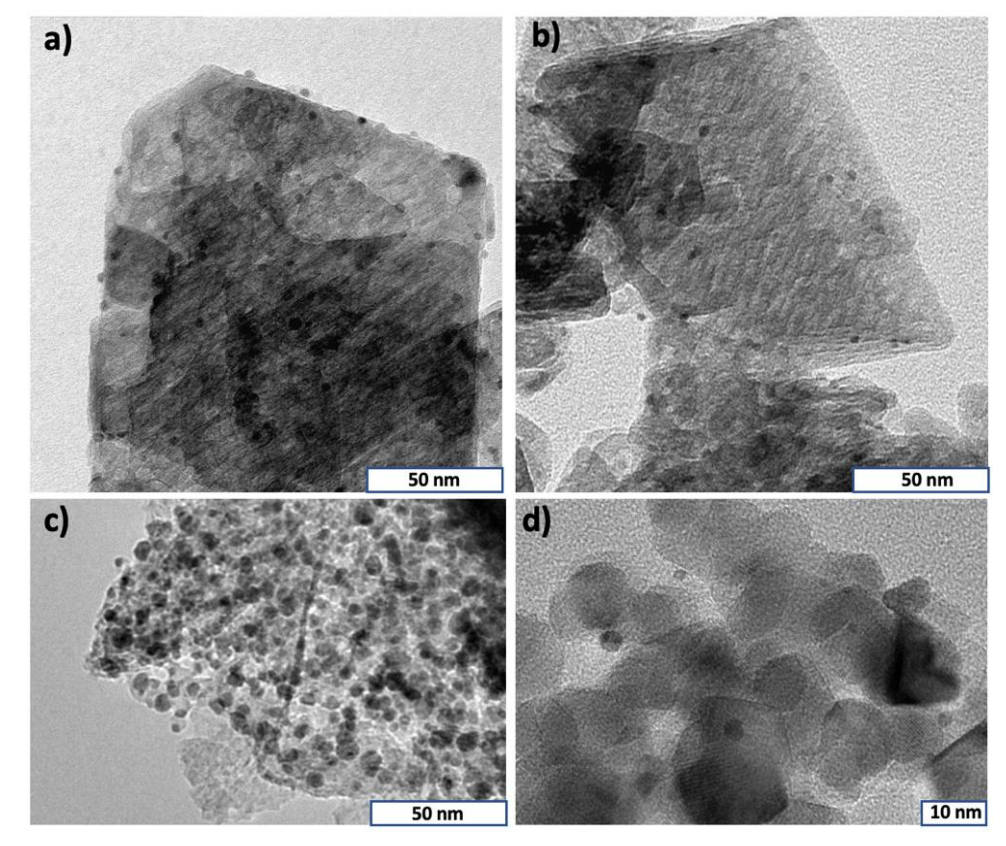

Figure 4 Transmission Electron Microscopy (TEM) images recorded for the $\mathrm{Au} / \mathrm{Al}_{2} \mathrm{O}_{3}(\mathrm{a}$, b), Au/HT 3:1 (c), and Au/MgO (d) catalysts.

\section{Discussion}

Prior to carrying out the partial reduction of FA to produce FF, preliminary studies were conducted to identify the optimal active catalyst. We have previously reported the catalytic performances of the Au/HTs catalysts used for the oxidation of FF to FA [32]. The catalytic performances of the $\mathrm{Au} / \mathrm{HT}$ catalysts under conditions of varying $\mathrm{Mg}$ :Al molar ratios (from 2:1 to 5:1) are presented in Table 3.

Table 3 Catalytic performance of the Au/HT catalyst during the oxidation of FF under conditions of varying Mg:Al molar ratios (Conditions: FF/Au molar ratio = 200:1, $25 \mathrm{mg}$ of catalyst, $\mathrm{P}_{\mathrm{O} 2}=6 \mathrm{bar}, 600 \mathrm{rpm}, \mathrm{T}=110^{\circ} \mathrm{C}, \mathrm{t}=2 \mathrm{~h}$ ) [32]. 


\begin{tabular}{|c|c|c|c|c|c|c|c|}
\hline Catalyst & Conversion FF (\%) & $\begin{array}{l}\text { Selectivity } \\
\text { (\%) }\end{array}$ & FA & $\begin{array}{l}\text { Yield } \\
(\%)\end{array}$ & FA & $\begin{array}{l}\text { Carbon } \\
(\%)\end{array}$ & Balance \\
\hline $\mathrm{Au} / \mathrm{HT}(5: 1)$ & 99 & 99 & & 99 & & 99 & \\
\hline $\mathrm{Au} / \mathrm{HT}(4: 1)$ & 99 & 99 & & 99 & & 99 & \\
\hline $\mathrm{Au} / \mathrm{HT}(3: 1)$ & 77 & 88 & & 68 & & 91 & \\
\hline $\mathrm{Au} / \mathrm{HT}(2: 1)$ & 83 & 85 & & 71 & & 89 & \\
\hline $\mathrm{Au} / \mathrm{MgO}$ & 100 & 99 & & 99 & & 99 & \\
\hline $\mathrm{Au} / \mathrm{Al}_{2} \mathrm{O}_{3}$ & 16 & 56 & & 9 & & 87 & \\
\hline
\end{tabular}

Roselli et al. [32] reported that when the Mg:Al molar ratio in the HT support was increased, the yield of FA increased from 70 to $100 \%$. However, the results obtained by conducting the stability tests confirmed a progressive deactivation of the catalyst, and this could be attributed to the leaching of the $\mathrm{Mg}^{2+}$ cations. Under these conditions, the $\mathrm{pH}$ of the reaction media increased. Excellent results were obtained when the Mg:Al molar ratios were 5:1 and 4:1. This could be attributed to the high basicity of the catalysts. The relationship between the basicity of the media (or support) and the catalytic performances has also been studied. Kikhtyanin et al. [36] studied the influence of basicity on the process of FF condensation carried out in the presence of acetone using different $\mathrm{HTs}$ characterized by a wide range of $\mathrm{Mg} / \mathrm{Al}$ compositions. They reported that the density of the basic sites present in the mixed oxides, especially the density of the strongly basic sites $\left(\mathrm{O}^{2-}\right.$ ions), significantly influenced the activity of the system during the reaction [36].

We decided to study the gold catalysts where the $\mathrm{Mg}: \mathrm{Al}$ molar ratio was between 3:1 and 1:3. $\mathrm{Au} / \mathrm{MgO}$ and $\mathrm{Au} / \mathrm{Al}_{2} \mathrm{O}_{3}$ catalysts were also studied as reference catalysts. The Au/HTs series, $\mathrm{Au} / \mathrm{MgO}$, and $\mathrm{Au} / \mathrm{Al}_{2} \mathrm{O}_{3}$ catalysts were tested, and the extents of FA conversion and space-time yields (STY) recorded for FF are shown in Figure 5.

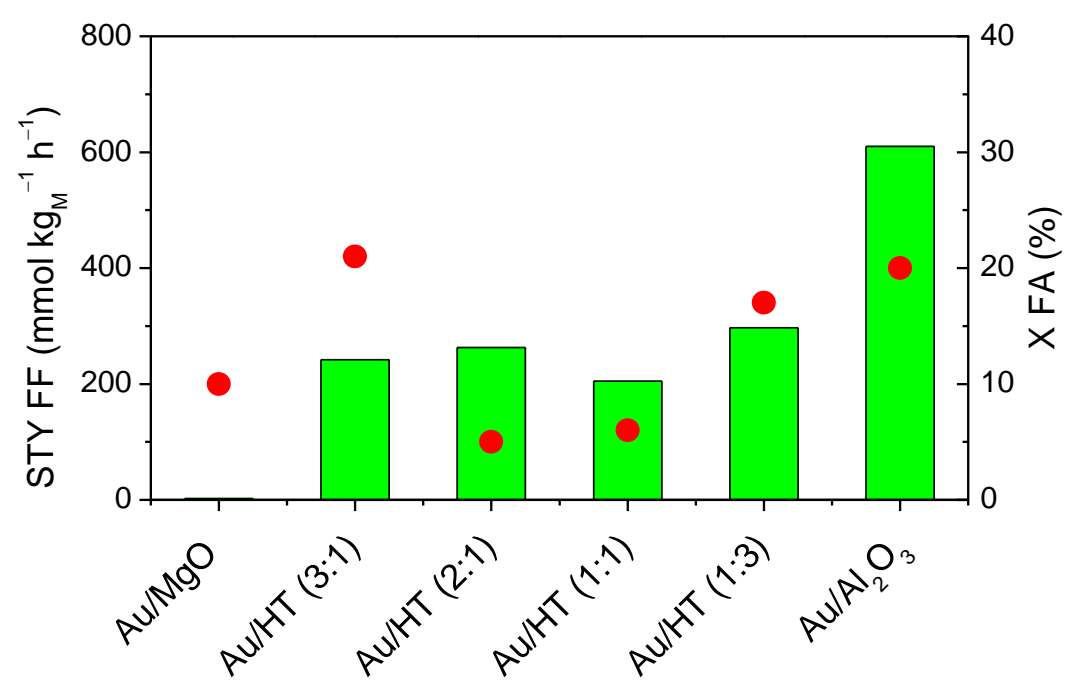

Figure 5 Effect of the support basicity in gold catalyst on the process of FA reduction: FA conversion (O) and the STY of FF $(\square)$ (Conditions: $15 \mathrm{mg} \mathrm{FA}, \mathrm{P}_{\mathrm{cO} 2}=15 \mathrm{bar}, 600 \mathrm{rpm}, \mathrm{T}=$ $150^{\circ} \mathrm{C}, \mathrm{t}=24 \mathrm{~h}, 20 \mathrm{~mL}$ of DMSO). 
Poor performances were recorded during the reduction of FA to FF when $\mathrm{MgO}$ was used as the support for gold catalysts (Figure 5). Only $10 \%$ of FA could be converted, and traces of FF were obtained. A series of HTs with varying Mg:Al ratios were studied, and excellent extents of conversion were recorded when the ratios were $3: 1$ and $1: 3$. At the ratios of $1: 1$ and $2: 1$, poor performances were recorded ( $5 \%$ FA conversion). Thus, Au/HTs can be potentially used to form FF from FA. The versatility of the Au/HTs catalysts during the aldehyde-acid, and acid-aldehyde catalytic transformations was confirmed. The activity of the $\mathrm{Au} / \mathrm{Al}_{2} \mathrm{O}_{3}$ catalyst was higher than the activity of the Au/HTs (3:1 and 1:3). The extent of conversion was $20 \%$, and the yield of FF increased. These results indicate that the acid-base properties of the support significantly influence the efficiency of the reaction. Yokoyama et al. [25] studied the acid-base properties of metal oxides and their influence on aldehyde selectivity. If the surface of the catalyst does not contain strong basic or acidic sites and if the catalysts are characterized by weak redox properties, the catalytic performances can be improved. $\mathrm{MgO}$ is a well-known metal oxide that contains strong basic sites $\left(\mathrm{O}^{2-}\right.$ ions) at the surface [27]. Similarly, HT supports also contain strong basic sites and Lewis acidic sites of weak to medium strengths [27, 32]. The strength depends on the $\mathrm{Mg}$ :Al molar ratio. It is generally considered that the surface of the $\mathrm{Al}_{2} \mathrm{O}_{3}$ support contains weak acidic sites [27]. We can correlate the catalytic performances with the acid-base properties of the catalysts. The best catalytic performances were recorded when the $\mathrm{Au} / \mathrm{Al}_{2} \mathrm{O}_{3}$ catalyst containing weak acidic sites were used.

\section{Conclusions}

The versatility of the Au/HTs catalysts, which were highly active during the oxidation of FF, has been tested during the partial reduction of FA to FF. Preliminary results confirmed the versatility of the gold supported on hydrotalcite systems. The reactions were carried out using DMSO as the solvent under the pressure of $\mathrm{CO}_{2}$. Furthermore, the best catalytic performance during the reduction of FA was recorded when $\mathrm{Au} / \mathrm{Al}_{2} \mathrm{O}_{3}$ was used as the catalyst. $\mathrm{Au} / \mathrm{MgO}$ was found to be inactive. The specific acid-base properties of the $\mathrm{Au} / \mathrm{Al}_{2} \mathrm{O}_{3}$ catalyst (containing strongly acidic or basic sites) correlated with the activity recorded during the direct reduction of FA. The Au/HTs and $\mathrm{Au} / \mathrm{MgO}$ catalysts containing strong basic sites were much less active.

\section{Acknowledgments}

The REALCAT platform is benefiting from a state subsidy administrated by the French National Research Agency (ANR), within the frame of the "Future Investments" program (PIA), with the contractual reference "ANR-11-EQPX-0037". The European Union, through the ERDF funding administered by the Hauts-de-France Region, co-financed the platform. Centrale Lille, the CNRS and Lille University, as well as the Centrale Initiative Foundation, are thanked for their financial contribution to the acquisition and implementation of the equipment of the REALCAT platform. The Métropole Européen de Lille (MEL) for the "CatBiolnnov" project is also acknowledged.

\section{Author Contributions}

Conceptualization, FD, YS and C.P.F.; methodology, FD.; formal analysis, FD, YS, MM and JTR; data curation, FD, YS, SH, JTR, MM, CPF and IIJ; writing-original draft preparation, FD, YS, IIJ and R.W.; writing-review and editing, CPF, YS and JTR, SH, MM, and SP; visualization, RW; supervision, RW; 
project administration, RW; funding acquisition, RW. All authors have read and agreed to the published version of the manuscript.

\section{Funding}

This research was funded by REGION HAUTS-de-FRANCE, grant number 3859523 FDCA STARTAIRR project and I-SITE ULNE grant V-Start'AIRR-18-001-Wojcieszak This study was supported by the French government through the Programme Investissement d'Avenir (I-SITE ULNE/ANR-16IDEX-0004 ULNE) managed by the Agence Nationale de la Recherche.

\section{Competing Interests}

The authors have declared that no competing interests exist.

\section{References}

1. Corma A, Iborra S, Velty A. Chemical routes for the transformation of biomass into chemicals. Chem Rev. 2007; 107: 2411-2502.

2. Dumeignil F, Capron M, Katryniok B, Wojcieszak R, Loefberg A, Girardon JS, et al. Biomassderived platform molecules upgrading through catalytic processes: Yielding chemicals and fuels. J Japan Pet Inst. 2015; 58: 257-273.

3. Drault F, Snoussi Y, Paul S, Itabaiana I, Wojcieszak R. Recent advances in carboxylation of furoic acid into 2, 5-furandicarboxylic acid: Pathways towards bio-based polymers. ChemSusChem. 2020; 13: 5164-5172.

4. Ferraz CP, Braga AH, Ghazzal MN, Zieliński M, Pietrowski M, Itabaiana I, et al. Efficient oxidative esterification of furfural using Au nanoparticles supported on group 2 alkaline earth metal oxides. Catalysts. 2020; 10: 430.

5. Zhang M, Li N, Tao X, Ruzi R, Yu S, Zhu C. Selective reduction of carboxylic acids to aldehydes with hydrosilane via photoredox catalysis. ChemComm. 2017; 53: 10228-10231.

6. Douthwaite M, Huang X, Iqbal S, Miedziak PJ, Brett GL, Kondrat SA, et al. The controlled catalytic oxidation of furfural to furoic acid using AuPd/Mg(OH) 2. Catal Sci Technol. 2017; 7: 5284-5293.

7. Thuriot-Roukos J, Khadraoui R, Paul S, Wojcieszak R. Raman spectroscopy applied to monitor furfural liquid-phase oxidation catalyzed by supported gold nanoparticles. ACS Omega. 2020; 5: 14283-14290.

8. Xiang $X$, Zhang B, Ding G, Cui J, Zheng $\mathrm{H}$, Zhu Y. The effect of $\mathrm{Mg}(\mathrm{OH})_{2}$ on furfural oxidation with $\mathrm{H}_{2} \mathrm{O}_{2}$. Catal Commun. 2016; 86: 41-45.

9. Mosettig E. The synthesis of aldehydes from carboxylic acids. Org React. 2004; 8: 218-257.

10. Four P, Guibe F. Palladium-catalyzed reaction of tributyltin hydride with acyl chlorides. A mild, selective, and general route to aldehydes. J Org Chem. 1981; 46: 4439-4445.

11. Gooßen L, Gooßen K, Rodríguez N, Blanchot M, Linder C, Zimmermann B. New catalytic transformations of carboxylic acids. Pure Appl Chem. 2008; 80: 1725-1733.

12. Kangani CO, Kelley DE, Day BW. One-pot synthesis of aldehydes or ketones from carboxylic acids via in situ generation of Weinreb amides using the Deoxo-Fluor reagent. Tetrahedron Lett. 2006; 47: 6289-6292. 
13. Akhtar MK, Turner NJ, Jones PR. Carboxylic acid reductase is a versatile enzyme for the conversion of fatty acids into fuels and chemical commodities. Proc Natl Acad Sci USA. 2013; 110: 87-92.

14. White $H$, Strobl G, Feicht $R$, Simon $H$. Carboxylic acid reductase: A new tungsten enzyme catalyses the reduction of non-activated carboxylic acids to aldehydes. Eur J Biochem. 1989; 184: 89-96.

15. Hollingworth GJ. Aldehydes: Aryl and heteroaryl aldehydes. Compr Org Funct Group Transform. 1995; 3: 81-109.

16. Chandrasekhar S, Kumar MS, Muralidhar B. One pot conversion of carboxylic acids to aldehydes with DIBAL-H. Prep Org Chem. 2010. Doi: 10.1002/chin.199819075.

17. Guyer A, Bieler A, Sommaruga M. Über die katalytische reduktion aliphatischer dicarbonsäuren und ihrer ester. Helv Chim Acta. 1955; 38: 976-982.

18. Aly M, Baumgarten E. Hydrogenation of hexanoic acid with different catalysts. Appl Catal A Gen. 2001; 210: 1-12.

19. Pestman R, Van Duijne A, Pieterse JA, Ponec V. The formation of ketones and aldehydes from carboxylic acids, structure-activity relationship for two competitive reactions. J Mol Catal A Chem. 1995; 103: 175-180.

20. Yokoyama T, Fujita N. Hydrogenation of dicarboxylic acid diesters to corresponding dialdehydes over $\mathrm{ZrO}_{2}$ based catalysts (Part 1) reactivity of various dicarboxylic acid diesters. J Japan Pet Inst. 2004; 47: 335-340.

21. Feinstein A, Fields EK, Standard Oil Co. Vapor phase conversion of aromatic esters to aromatic aldehydes. Washington, DC: United States patent; 1974; 3,935,265.

22. Manyar HG, Paun C, Pilus R, Rooney DW, Thompson JM, Hardacre C. Highly selective and efficient hydrogenation of carboxylic acids to alcohols using titania supported Pt catalysts. Chem Commun. 2010; 46: 6279-6281.

23. Takeda $Y$, Nakagawa $Y$, Tomishige $K$. Selective hydrogenation of higher saturated carboxylic acids to alcohols using a $\mathrm{ReO}_{x}-\mathrm{Pd} / \mathrm{SiO}_{2}$ catalyst. Catal Sci Technol. 2012; 2: 2221-2223.

24. Pritchard J, Filonenko GA, Van Putten R, Hensen EJ, Pidko EA. Heterogeneous and homogeneous catalysis for the hydrogenation of carboxylic acid derivatives: History, advances and future directions. Chem Soc Rev. 2015; 44: 3808-3833.

25. Yokoyama T, Yamagata N. Hydrogenation of carboxylic acids to the corresponding aldehydes. Appl Catal A Gen. 2001; 221: 227-239.

26. Sakata $\mathrm{Y}$, Ponec V. Reduction of benzoic acid on $\mathrm{CeO}_{2}$ and, the effect of additives. Appl Catal $A$ Gen. 1998; 166: 173-184.

27. Shen J, Kobe JM, Chen Y, Dumesic JA. Synthesis and surface acid/base properties of magnesiumaluminum mixed oxides obtained from hydrotalcites. Langmuir. 1994; 10: 3902-3908.

28. Bergadà $O$, Salagre $P$, Cesteros $Y$, Medina F, Sueiras JE. Adsorption of carbon dioxide in several aged hydrotalcites and calcined hydrotalcites: Influence of microwave irradiation during the ageing step on their basic properties. Adsorp Sci Technol. 2007; 25: 143-154.

29. Gupta NK, Nishimura S, Takagaki A, Ebitani K. Hydrotalcite-supported gold-nanoparticlecatalyzed highly efficient base-free aqueous oxidation of 5-hydroxymethylfurfural into 2, 5furandicarboxylic acid under atmospheric oxygen pressure. Green Chem. 2011; 13: 824-827.

30. Hattori H. Heterogeneous basic catalysis. Chem Rev. 1995; 95: 537-558. 
31. Tathod A, Kane T, Sanil ES, Dhepe PL. Solid base supported metal catalysts for the oxidation and hydrogenation of sugars. J Mol Catal A Chem. 2014; 388: 90-99.

32. Roselli A, Carvalho Y, Dumeignil F, Cavani F, Paul S, Wojcieszak R. Liquid phase furfural oxidation under uncontrolled $\mathrm{pH}$ in batch and flow conditions: The role of in situ formed base. Catalysts. 2020; 10: 73.

33. Zhao R, Yin C, Zhao H, Liu C. Synthesis, characterization, and application of hydotalcites in hydrodesulfurization of FCC gasoline. Fuel Process Technol. 2003; 81: 201-209.

34. Dimitratos N, Lopez-Sanchez JA, Morgan D, Carley A, Prati L, Hutchings GJ. Solvent free liquid phase oxidation of benzyl alcohol using Au supported catalysts prepared using a sol immobilization technique. Catal Today. 2007; 122: 317-324.

35. Habibi $\mathrm{N}$, Arandiyan $\mathrm{H}$, Rezaei $\mathrm{M}$. Mesoporous $\mathrm{MgO} \cdot \mathrm{Al}_{2} \mathrm{O}_{3}$ nanopowder-supported mesomacroporous nickel catalysts: A new path to high-performance biogas reforming for syngas. RSC Adv. 2016; 6: 29576-29585.

36. Kikhtyanin O, Čapek L, Smoláková L, Tišler Z, Kadlec D, Lhotka M, et al. Influence of Mg-Al mixed oxide compositions on their properties and performance in aldol condensation. Ind Eng Chem Res. 2017; 56: 13411-13422.

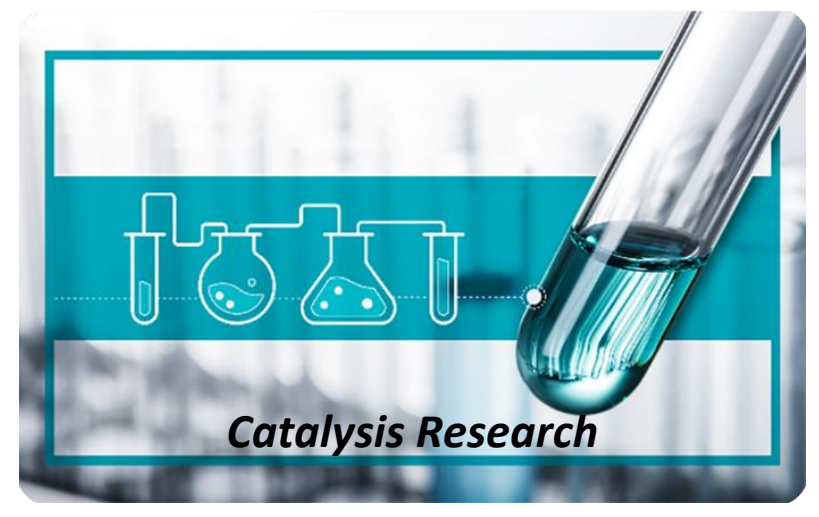

Enjoy Catalysis Research by:

1. Submitting a manuscript

2. Joining in volunteer reviewer bank

3. Joining Editorial Board

4. Guest editing a special issue

For more details, please visit: http://www.lidsen.com/journals/cr 